\title{
DETERMINAÇÃO DO ÍNDICE DE COLIFORMES FECAIS DO BALNEÁRIO VENEZA EM CAXIAS (MA)
}

\author{
DETERMINATION OF FAECAL COLIFORM INDEX OF VENEZA BALNEARY IN \\ CAXLAS (MA)
}

Wiliana Francisca de Sá Vieira ${ }^{1}$
Daniel Silas Veras-dos-Santos ${ }^{2}$
Paulo Sérgio da Silva Moraes ${ }^{3}$

RESUMO: No perímetro urbano da cidade de Caxias-MA se localiza o balneário Veneza, que proporciona atividades de contanto primário neste é de fundamental importância o monitoramento da qualidade de sua água para verificar se a mesma está de acordo com os critérios de balneabilidade estabelecidos na Resolução CONAMA 274/2000 que estabelece um índice microbiológico de Coliformes fecais, nesse sentido o prente trabalho teve por objetivo realizar o biomonitoramento do Balneário Veneza para a classificação da sua água em próprias ou improprias de acordo com os índices de Coliformes fecais dispostos na Resolução CONAMA 274/2000, o biomonitoramento foi realizado durante dez semanas nos pontos de maior fluxo de banhistas através da cartela colipaper, os resultados obtidos, bem como os dados da literatura permitiram concluir que as águas do balneário no ponto 1 são recomendadas paras usos de contato primário, no entanto, as águas no ponto 2 encontra-se improprias para o uso, oferecendo risco de saúde a toda população.

PALAVRAS-CHAVE: Análise microbiológica, biomonitoramento, balneabilidade.

ABSTRACT: Within the city limits of the city of Caxias (MA) is located the Veneza balneary that provides primary activities provided this is extremely important to monitor the quality of your water to see if it complies with the criteria set out in bathing CONAMA Resolution 274/2000, which establishes a microbiological index of fecal coliforms in that sense the prente study aimed to conduct biomonitoring of Veneza balneary for the classification of their own water or improper according to the levels of Fecal coliforms arranged by CONAMA Resolution $274 / 2000$, biomonitoring was held for ten weeks basis points greater flow of bathers by colipaper chart, the results obtained and the literature data showed that the balneary waters in point 1 are recommended paras primary contact uses, however, the waters in point 2 is found unfit for use, posing a risk of health the entire population.

KEYWORDS: Microbiological analysis, biomonitoting, bathing.

\footnotetext{
1 Técnica em Meio Ambiente. Instituto Federal do Maranhão Campus Caxias. email: wilianavieiradesa@hotmail.com

${ }^{2}$ Professor do Instituto Federal do Maranhão Campus Caxias. email: daniel.veras@,ifma.edu.br

${ }^{3}$ Professor do Instituto Federal do Maranhão Campus Caxias. email: paulo.moraes@ifma.edu.br
} 


\section{INTRODUÇÃO}

A água é um bem essencial à vida, tanto por ser necessária para a ocorrência do metabolismo dos seres vivos, quanto para o desenvolvimento de atividades produtivas e de lazer dos seres humanos mas para os diversos usos da água há a exigência de determinados padrões de qualidade, para que se possa garantir a salubridade das suas utilizações.

A ação predatória, no ambiente, tem gerado a degradação da qualidade da água, a contaminação dos corpos hídricos, sobretudo com esgoto sanitário, tem aumentando muito o risco de transmissão de doenças, ainda mais quando esses locais são utilizados pela população para a prática de ecoturismo, que exige a ocorrência de um contato primário com a água (MARIANO, 2008).

Segundo dados da Organização Mundial da Saúde - OMS (outubro de 2003) e do Instituto Brasileiro de Geografia e Estatística - IBGE (março de 2004), cerca de 85\% das doenças conhecidas são de veiculação hídrica, ou seja, estão relacionadas à água (TAVARES, 2008).

As doenças de veiculação hídrica são ocasionadas, principalmente por microrganismos patogênicos de origem entérica, animal ou humana, transmitida basicamente pela rota fecal-oral, ou seja, são excretados nas fezes de indivíduos infectados e ingeridos com a água ou alimento contaminado pela água poluída com fezes (GREGHI, 2005).

Considerando que a saúde e o bem-estar humano podem ser afetados pelas condições de balneabilidade. É essencial à defesa dos níveis de qualidade, avaliados por parâmetros e indicadores específicos, de modo a assegurar as condições necessárias à recreação de contato primário (CONAMA, 2000).

Portanto, o objetivo do presente trabalho foi realizar o monitoramento microbiológico do Balneário Veneza em Caxias (MA).

\section{METODOLOGIA}

\section{Área de estudo}

O monitoramento foi realizado no balneário Veneza (Figura 1) no município de CaxiasMaranhão, o qual está localizado na região dos Cocais, o mesmo pertence à Zona fisiográfica do Itapecuru, situado na mesorregião do leste maranhense apresentando as seguintes coordenadas geográficas, latitude $04^{\circ} 53^{\prime} 30^{\prime \prime}$ longitude 4324'53”W, com altitude aproximada de 66 metros. 
Os pontos de maior fluxo de banhistas foram determinados pela observação in loco do Balneário e posteriormente referenciados através de GPS GARMIN Etrex $3004^{\circ} 54^{\circ} 849^{\prime \prime} \mathrm{S} /$

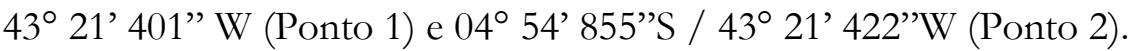

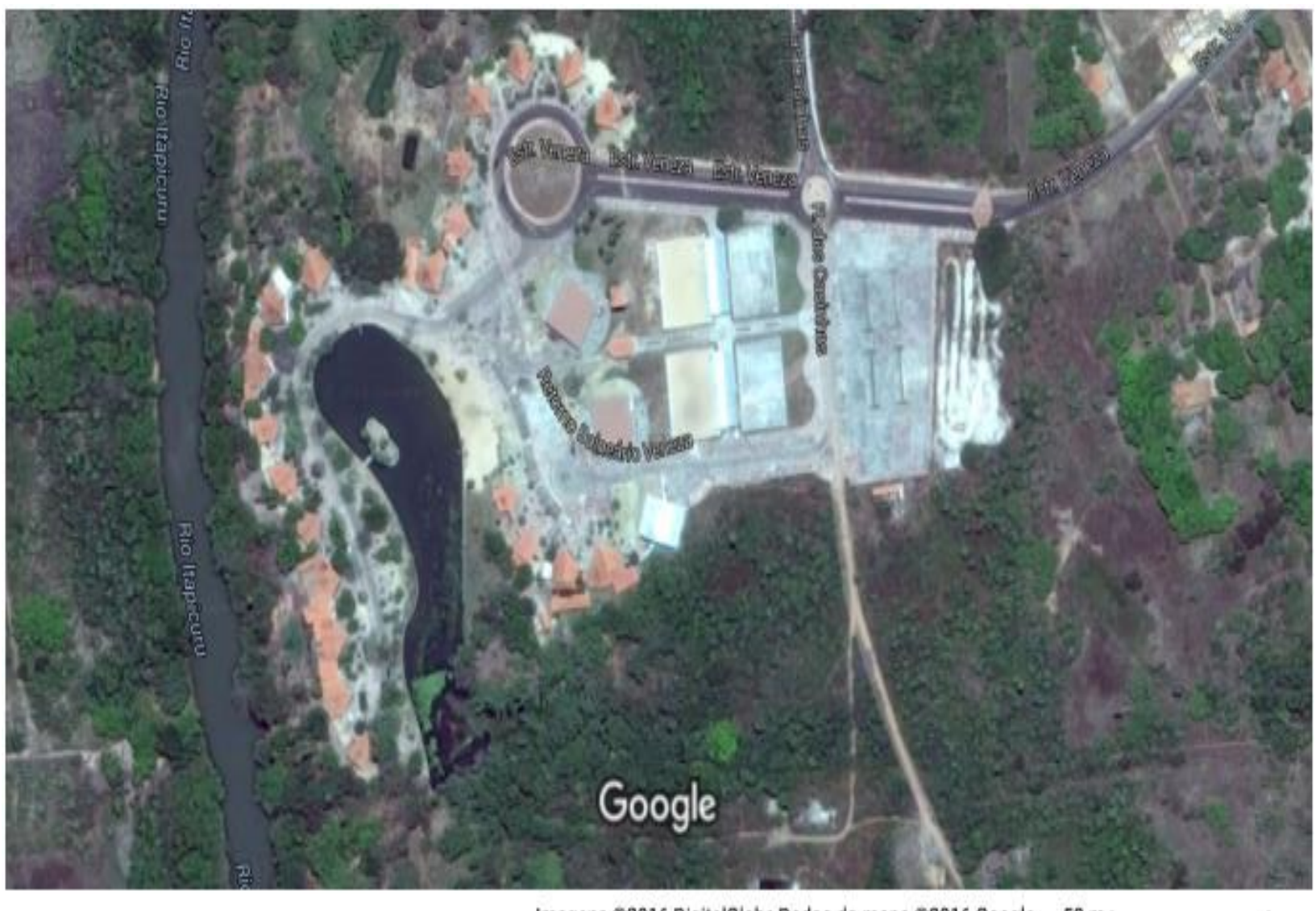

Imagens @2016 DigitalGlobe,Dados do mapa @2016 Google $50 \mathrm{~m}$

Figura 1: Balneário Veneza, Caxias (MA). Fonte: Google mapas, 2016.

\section{Análise Microbiológicas}

Foram realizadas 10 análises, de 07/07/2013 a 13/10/2013, com a cartela microbiológica Colipaper que consiste na combinação de dois substratos cromogênicos (Salmon-GAL e X glicuronídeo) que possibilita a detecção de coliformes totais e fecais (Termotolerantes), em uma mesma cartela (VILLELA, 2010).

Os procedimentos a serem seguidos foram os especificados no manual da colipaper.

A quantificação dos resultados consistiu na contagem dos pontos azuis (colônias de coliformes fecais) e a contagem dos pontos azuis e vermelhos (colônias de coliformes totais) e a multiplicação dos mesmos por 100, obtendo-se os resultados em UFC/100 mL.

Após a obtenção dos resultados da contagem de C. fecais os mesmos foram comparados com os parâmetros estabelecidos pela resolução CONAMA no 274/2000 na tabela 1 para determinação da categoria de balneabilidade das águas do Balneário Veneza. 
Quadro 1: Categoria das águas doces destinadas a balneabilidade adaptado da Resolução CONAMA 274/2000

Categoria

Excelente

Muito boa

Satisfatória

Imprópria

\section{Própria}

Quando 80\% do número de amostras coletadas nas cinco semanas anteriores, em um mesmo local, apresentarem um limite de: 250 Coliformes Fecais, 200 Escherichia coli por 100 mililitros.

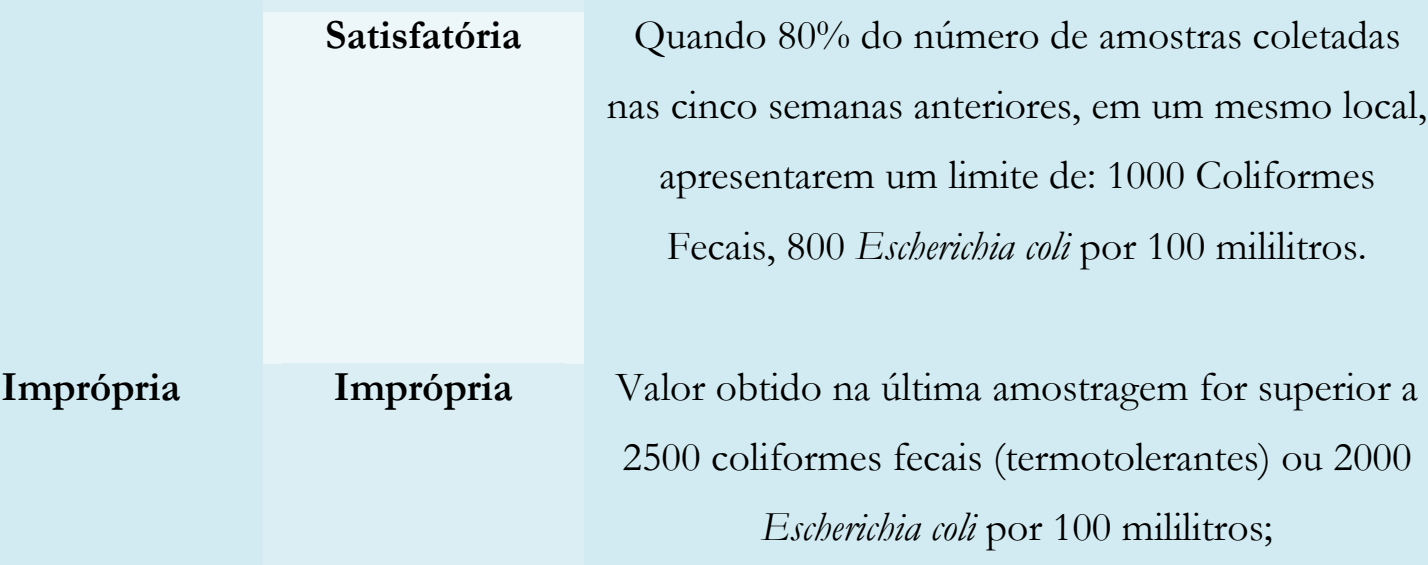

Fonte: Resolução CONAMA nº 274/2000.

\section{RESULTADOS E DISCUSSÃO}

Para classificação dos pontos de análise nas respectivas categorias, estabelecidas pela resolução CONAMA n ${ }^{\circ}$ 274/2000, comparou-se os resultados obtidos para coliformes fecais nos Pontos 1 e 2 com os limites fixados pela referida resolução, obtendo-se respectivamente as respectivas figuras 3 e 4 . 


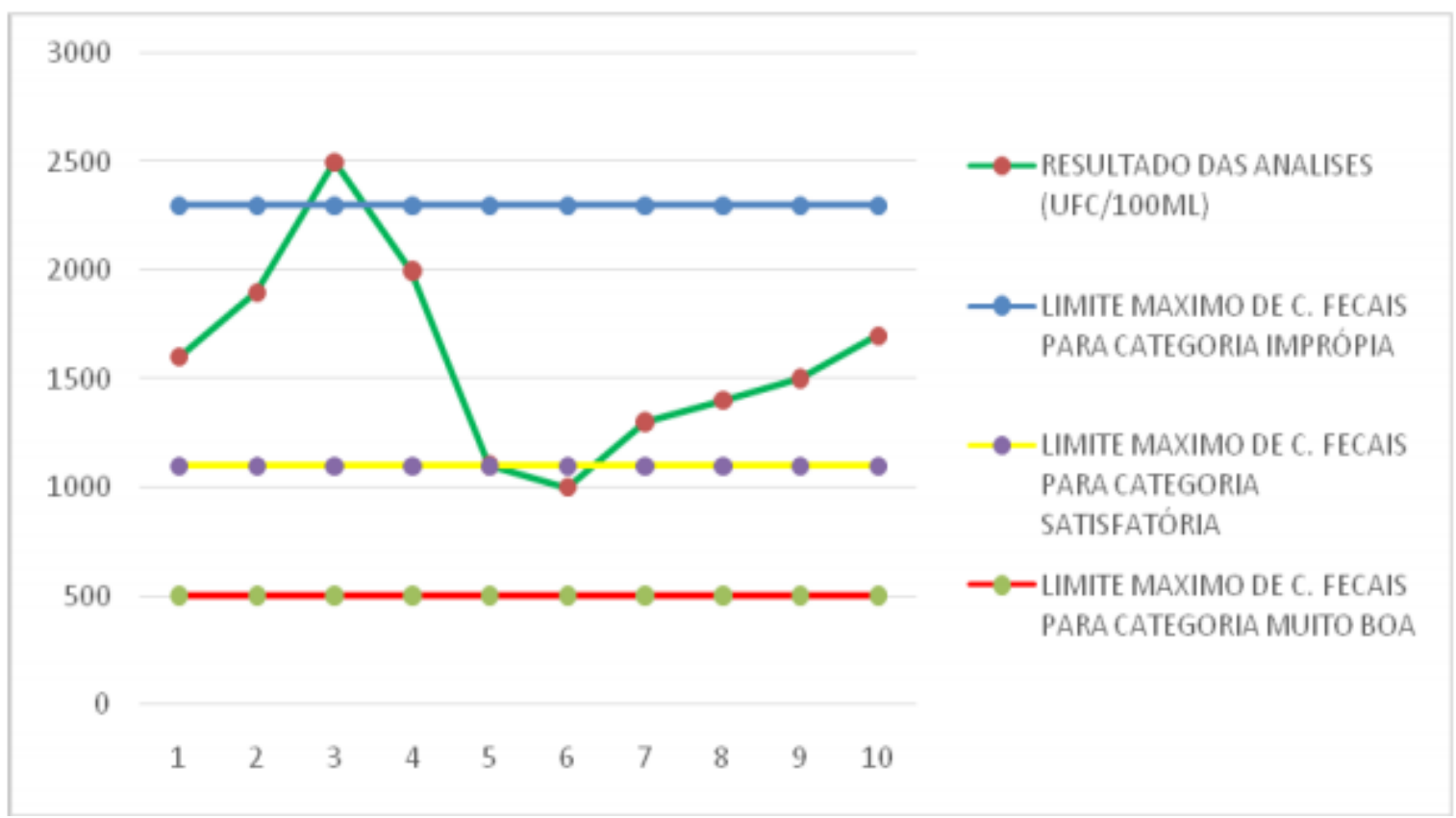

Figura 3: Comparação dos resultados da enumeração de coliformes fecais no Ponto 1 com os parâmetros dispostos na resolução CONAMA no 274/2000. Fonte: VIEIRA, W. F. S., 2013.

De acordo com figura 2, observa-se que das dez amostras obtidas, oito estão nos valores de 1000UFC/ $100 \mathrm{~mL}$ a $1900 \mathrm{UFC} / 100 \mathrm{~mL}$ representando $80 \%$ das mesmas, assim, pode-se classificar o Ponto 1 na categoria de águas satisfatórias para balneabilidade.

Nesse sentido, a probabilidade de infcções gastrointestinais é menor do que nas águas de recreação expostas a contaminação de bactérias fecais e considerdas improprias, as quais estão relacionadas com gastroenterites (WHO, 2003).

Observa-se que na terceira amostra houve um pico elevado de coliformes fecais de 2500UFC/100mL tal fato pode estar relacionado à presença elevada de pessoas que estavam participando de recreações no entorno e devido a uma precipitação ocorrida durante a manhã.

Em um estudo realizado na barragem do Bezerro em José de Freitas (PI), verificou-se que houve um pico de coliformes fecais de $1.700 \mathrm{UFC} / 100 \mathrm{~mL}$ e que no local havia ocorrido uma precipitação durante a madrugada, além da presença de muitos banhistas (VERAS-DOSSANTOS; MENDES-CAMARA, 2013).

Nas amostras 5 e 6 observa-se um decréscimo no nível de coliformes fecais, isso pode está relacionado a uma intervenção realizada pela prefeitura municipal na qual realizou-se uma limpeza realizada entre 15/08 e 5/09. 


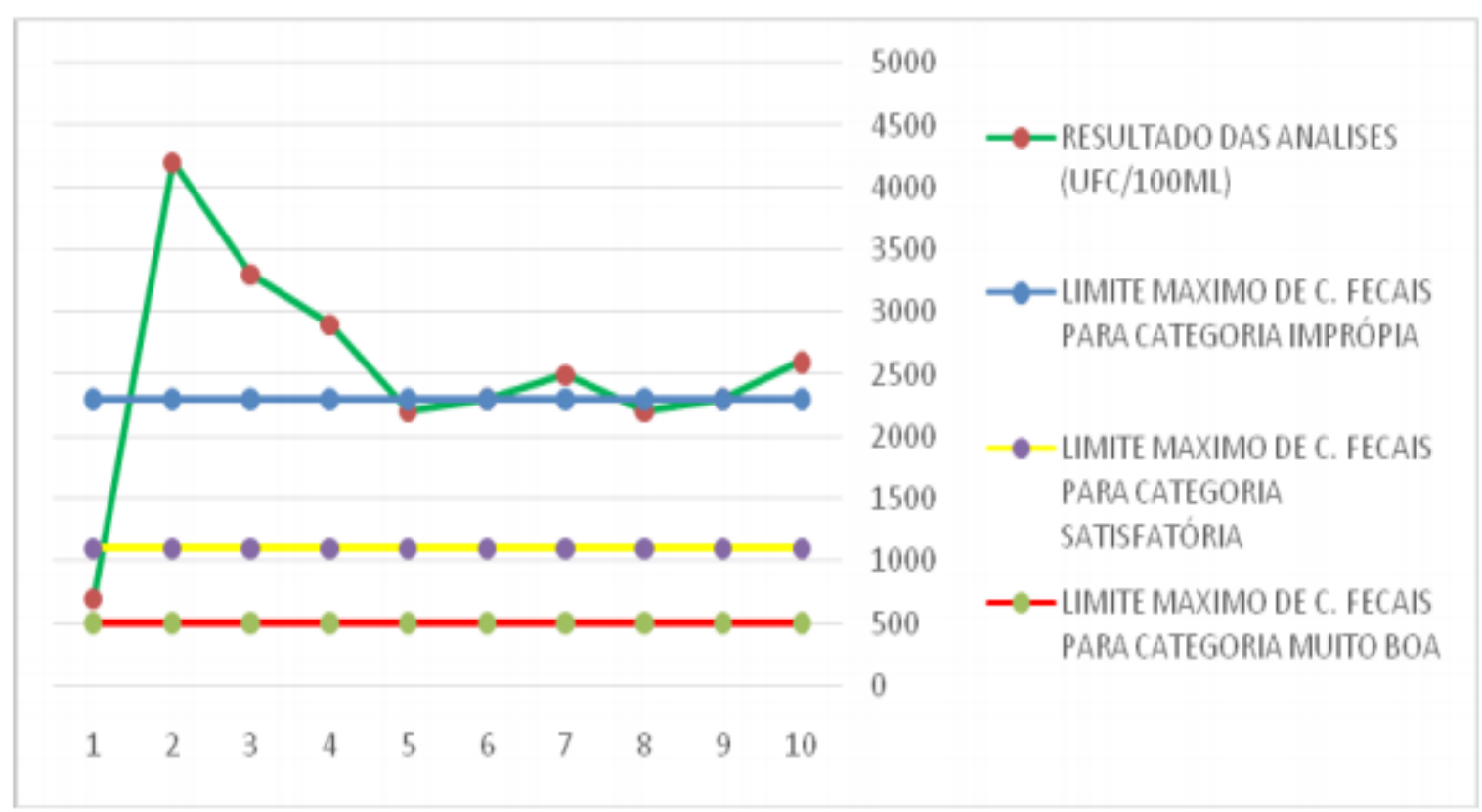

Figura 4: Comparação dos resultados da enumeração de coliformes fecais no Ponto 2 com os parâmetros dispostos na resolução CONAMA no 274/2000. Fonte: VIEIRA, W. F. S., 2013.

A análise da figura 2 permite verificar que das dez amostras obtidas, nove estão entre 2200 UFC/100 ml e $4200 \mathrm{UFC} / 100 \mathrm{ml}$, representando 90\% das mesmas, portanto no Ponto 2 as águas são classificadas na categoria de águas impróprias para balneabilidade.

Em uma avaliação da balneabilidade e qualidade da água da represa laranja-doce no município de Martinópolis-SP, verificou-se que a balneabilidade em 100\% das amostras mantevese com classificação "Imprópria", com um pico de 120.000 UFC. $100 \mathrm{~mL}^{-1}$ de coliformes fecais, devido à maior concentração de pessoas no local, por se tratar de uma área com condomínios construídos (SCANDELAI; SOLINA; SOUZA, 2012).

Alguns dos fatos que podem explicar os altos índices de contaminação do ponto 2 é o despejo de efluentes domésticos não tratados dos restaurantes e residências, visto que essa área não apresenta redes de coleta de esgotos, fato que é agravado pelos banhistas e clientes dos bares que se situam no entorno do Balneário Veneza, que também acabam por contribuir com essa contaminação pelo descarte de restos de alimentos.

Em estudo microbiológico realizado no balneário Veneza em 2009 foi observado que suas águas já estavam apresentando crescentes índices de contaminação fecal (SILVA; FREITAS; CARVALHO, 2011).

\section{CONSIDERAÇÕES FINAIS}

As análises realizadas permitem concluir que o Ponto 1 e o Ponto 2 estudados são classificadas, respectivamente, nas categorias água satisfatória e impróprias para balneabilidade. 
Com os resultados obtidos, bem como, os dados da literatura nos permitiram concluir que as águas do balneário Veneza no ponto 1 são recomendadas paras usos de contato primário, no entanto, as águas no ponto 2 encontra-se impróprias para o uso, oferecendo risco de infecções aos usuários.

Além disso, pode-se perceber que as precipitações e atividades realizadas no entorno do balneário influenciam diretamente os parâmetros considerados para a classificação das águas para balneabilidade estabelecidas pela resolução CONAMA nº 274/2000.

Tendo em vista a ocorrência de pontos impróprios para o banho, se faz necessário medidas de educação ambiental e saneamento básico com o intuito de esclarecer a moradores e visitantes do balneário, sobre a necessidade de conservação das fontes de água do local e a valorização do potencial turístico para a região.

\section{AGRADECIMENTOS}

Ao IFMA e ao CNPq pela concessão de bolsa IC Jr IFMA/CNPq.

\section{REFERENCIAS}

APHA, AWWA, WEF, standandwethods for the exumination of water and wastewate, usted, 2005 .

BARATELA-SIMM, K.C.; SPIASSI, A.; VECHIATTO, C.V.; CASARIL, S.; MOURA A. C. Análise microbiológica da água nos principais mananciais de abastecimento de Cascavel, PR. Revista Higiene Alimentar, n 1, v.22, outubro 2008. p 65- 67.

CONAMA, 2000. Resolução CONAMA $\mathbf{n}^{\circ}$ 274, de 29 de novembro de 2000. Brasília-DF (Brasil), Conselho Nacional de Meio Ambiente, Ministério do Meio Ambiente.

GREGHI, S. Q. Avaliação da eficiência de métodos rápidos usados para a detecção de Coliformes Totais e Coliformes Fecais em amostras de água em comparação técnicas de fermentação em tubos múltiplos. Universidade Estadual Paulista: Araraquara, 2005.

MARIANO, M. B.; VIDAL, C. M. S.; SOUSA, J. B. Avaliação da Qualidade Microbiológica da Água para Balneabilidade do Salto Manduri, Prudentópolis - PR. VI Semana da Engenharia Ambiental, Campus Irati, Prudentópolis, 2008.

SCANDELAI, A. P. J; SOLINA, M. R. F e SOUZA, A. T. AVALIAÇÃO DA BALNEABILIDADE E QUALIDADE DA ÁGUA DA REPRESA LARANJA-DOCE NO MUNICÍPIO DE MARTINÓPOLIS-SP. Colloquium Exactarum, v. 4, n.2, Jul-Ago. 2012, p. 31 - 36. DOI: $10.5747 /$ ce.2012.v04.n2.e048. 
SILVA,E. O.; FREITAS, C. F. e CARVALHO, L. C. ANÁLISE MICROBIOLÓGICA DA ÁGUA DO BALNEÁRIO VENEZA NO MUNICÍPIO DE CAXIAS-MA, BRASIL. Revista ACTA Tecnológica - Revista Científica - ISSN 1982-422X, Vol. 6, número 1, jan-jun. 2011.

TAVARES, S. R. L. et al. Curso de recuperação de áreas degradadas: a visão da Ciência do Solo no contexto do diagnostico, manejo, indicadores de monitoramento e estratégias de recuperação. Rio de Janeiro: Embrapa Solos, 2008. p. 125-132.

VERAS-DOS SANTOS, D. S.; MENDES-CAMARA, F. M. Avaliação da Qualidade da Água para Balneabilidade da Barragem do Bezerro, localizada em José de Freitas - PI. In: V encontro de produtividade em pesquisa e V de iniciação cientifica do IFPI, 5, 2013, Teresina. Anais... São Paulo: IFPI, 2013.

VILLELA, L. C.; CALDAS, V. T.; GAMBA, R. C. Análise Microbiológica em Águas Minerais envasadas em embalagens de $510 \mathrm{ml}$, comercializadas no Município de Santos - SP. Revista Ceciliana, São Paulo, p. 4-6, jun. 2010. 